\title{
Glycine supplemented oral rehydration solutions for diarrhoea
}

\author{
T VESIKARI AND E ISOLAURI
}

Department of Clinical Sciences, University of Tampere, and Department of Paediatrics, Tampere University Central Hospital, Tampere, Finland

SUMmaRY Two glycine supplemented oral rehydration solutions (ORS) and a standard ORS with sodium $60 \mathrm{mmol} / \mathrm{l}$ were compared for treatment of diarrhoeal dehydration in children. The solutions contained glycine $110 \mathrm{mmol} / \mathrm{l}$ and glucose $110 \mathrm{mmol} / 1\left(\mathrm{ORS}_{60}-\mathrm{Gly}_{110}\right)$, glycine 60 $\mathrm{mmol} / \mathrm{l}$ and glucose $80 \mathrm{mmol} / \mathrm{l}\left(\mathrm{ORS}_{60}-\mathrm{Gly}_{60}\right)$, and glucose $144 \mathrm{mmol} / \mathrm{l}$ only $\left(\mathrm{ORS}_{60}\right)$, respectively. The patients receiving $\mathrm{ORS}_{60}$-Gly ${ }_{110}$ had poor weight gain and increased stool and urine volumes after rehydration compared with the other two groups. The patients receiving $\mathrm{ORS}_{60}-\mathrm{Gly}_{60}$ had similar stool and urine volumes as those receiving standard $\mathrm{ORS}_{60}$. It is concluded that excess glycine in relation to sodium in an ORS may lead to osmotic diarrhoea, and a high amount of absorbed glycine may result in osmotic diuresis with poor net rehydration. Altogether, the present study failed to find any improvement ('Super-ORS') by addition of glycine to an ORS containing $60 \mathrm{mmol} / \mathrm{l}$ of sodium.

Oral rehydration solution with the composition recommended by the World Health Organisation (WHO) (sodium $90 \mathrm{mmol} / \mathrm{l}$, glucose $111 \mathrm{mmol} / \mathrm{l}$, ORS-WHO) has proved to be highly successful for the correction of dehydration associated with diarrhoea of diverse origin. ${ }^{1}$ There is evidence, however, that modifications in the composition of ORS-WHO may further enhance water absorption in the intestines and improve rehydration..$^{2-4}$ Addition of amino acids or dipeptides to ORS-WHO has been suggested and experimented with, ${ }^{23}$ as many amino acids, such as glycine, stimulate sodium coupled water absorption from the gut independently from glucose. .7 $^{\text {A }}$ glycine-glucose solution ('Super-ORS') might not only utilise the sodium available in ORS but also return the flux of excreted sodium to net absorption of sodium and water, thus acting as an absorption promoting drug. ${ }^{3}$

We have previously shown that an ORS containing sodium $60 \mathrm{mmol} / \mathrm{l}$ and glucose $144 \mathrm{mmol} / \mathrm{l}$ $\left(\mathrm{ORS}_{60}\right)$ is equally effective as ORS-WHO for the correction of diarrhoeal dehydration in children in our conditions. ${ }^{8}$ The sodium concentration of 60 $\mathrm{mmol} / \mathrm{l}$ is also sufficient for replacement of sodium deficit in mild to moderate diarrhoeal dehydration with the amounts of fluid that can be administered in the first six hours. ${ }^{8}$ We therefore recommend $\mathrm{ORS}_{60}$ for the treatment of paediatric diarrhoea in Finland.
In the present study we wanted to find out if the properties of our ORS $_{60}$ could be improved by adding glycine but retaining sodium at $60 \mathrm{mmol} / \mathrm{l}$. The first modification contained $110 \mathrm{mmol} / \mathrm{l}$ glycine and $110 \mathrm{mmol} / \mathrm{l}$ glucose. Thus the solution resembled that used by Patra and Mahalanabis except for lower sodium concentration. ${ }^{3}$ When in the course of the study this solution seemed to cause problems the composition was changed to glycine $60 \mathrm{mmol} / \mathrm{l}$ and glucose $80 \mathrm{mmol} / \mathrm{l}$-that is, the total glycine +glucose is $140 \mathrm{mmol} / \mathrm{l}$, which is close to the molar concentration of glucose $(144 \mathrm{mmol} / \mathrm{l})$ in our standard ORS 6 . The three solutions could be tested in comparable groups of children with acute diarrhoeal dehydration.

\section{Patients and methods}

The study was carried out at the Department of Paediatrics, Tampere University Central Hospital, from February to May 1985. In the beginning of the study children under 5 years of age admitted for acute diarrhoeal dehydration were randomly allocated to receive either standard $\mathrm{ORS}_{60}$ or glycine supplemented $\mathrm{ORS}_{60}-\mathrm{Gly}_{110}$ for oral rehydration. Thus the study was randomised but not double blind-that is, the rehydration solutions were not code labelled. In the course of the trial it became 
apparent that some patients receiving $\mathrm{ORS}_{60}-\mathrm{Gly}_{110}$ were not responding well, and we decided to reduce the glycine concentration and total osmolality of the solution, and $\mathrm{ORS}_{60}-\mathrm{Gly}_{60}$ replaced $\mathrm{ORS}_{60}-\mathrm{Gly}_{110}$. Since the introduction of $\mathrm{ORS}_{60}-\mathrm{Gly}_{60}$ three quarters of the admitted patients were randomised to receive this solution and one quarter $\mathrm{ORS}_{60}$. The total numbers of patients in each group were 18 in the group treated with $\mathrm{ORS}_{60}-\mathrm{Gly}_{110}, 16$ in the group treated with $\mathrm{ORS}_{60}-\mathrm{Gly}_{60}$, and 22 in the group treated with $\mathrm{ORS}_{60}$.

The compositions of the three solutions are presented in Table 1. The composition of $\mathrm{ORS}_{60}$ was as described previously, ${ }^{8}$ including bicarbonate 30 $\mathrm{mmol} / \mathrm{l}$. In the other solutions, however, citrate was used instead of bicarbonate, as now recommended by WHO for ORS-WHO. ${ }^{1}$

The patients were examined on admission by the paediatrician on duty, and the decision to admit the patient to hospital was made by clinical judgment. The degree $(\%)$ of dehydration was estimated on admission using available information of the patient's preadmission weight and clinical signs. 'Acute weight loss' was calculated as the difference between the actual weight and the expected weight of the child as taken from his or her growth chart, and this was then used as a basis of rehydration therapy. The amount of fluid to be administered was $2 \times 2 / 3 \times$ acute weight loss within six hours. Between six and 12 hours after the beginning of treatment the same ORS was given as maintenance fluid, the amount being $1 / 4$ of the 24 hour need of water calculated from the standard formula: $100 \mathrm{ml} / \mathrm{kg}$ up to $10 \mathrm{~kg}$ of body weight, $50 \mathrm{ml} / \mathrm{kg}$ between 10 and $20 \mathrm{~kg}$ of body weight, and $20 \mathrm{ml} / \mathrm{kg}$ over $20 \mathrm{~kg}$. From 12 hours on an attempt was made to introduce a full normal diet for age, including normal drink.

Blood specimens were collected on admission and six, 12, and 24 hours after the beginning of treatment for the determination of serum electrolytes and total plasma protein concentrations, blood acid-base analysis, and packed cell volume. Urine

Table 1 Composition of the oral rehydration solutions used in the study (mmol/l)

\begin{tabular}{lccc}
\hline & $O R S_{60}-G l y_{110}$ & $O R S_{60}-G l y_{60}$ & $O R S_{60}$ \\
\hline Sodium & 60 & 60 & 60 \\
Potassium & 20 & 20 & 20 \\
Chlorine & 50 & 50 & 50 \\
Bicarbonate & - & - & 30 \\
Citrate & 10 & 80 & - \\
Glucose & 110 & 60 & - \\
Glycine & 110 & $\overline{280}$ & $\overline{304}$ \\
Osmolality (mOsm/l) & $\mathbf{3 6 0}$ & & \\
\hline
\end{tabular}

was collected in periods of zero to six, six to 12 , and 12 to 24 hours. Stools were quantified in periods of zero to 24 and 24 to 48 hours. In young children the soiled diapers were weighed and the weight of dry clean diapers was deducted, urine contamination being avoided by the use of urine collection bags. The patients were weighed after the 12 hours' period of rehydration and daily from then onwards. In addition, the consistency (solid, loose, or watery) of all stools passed by the child was recorded. The last occurrence of watery stools was used for the calculation of the duration of diarrhoea.

The presence of rotavirus in stools was shown with an enzyme immunoassay (Rotazyme II, Abbott Laboratories). The stools were also cultured for salmonella, shigella, yersinia, and campylobacter, but none of these enteropathogens were discovered.

The study protocol was reviewed and approved by the hospital's ethical committee. Statistical calculations were performed using the statistical data processing system of the University of Tampere.

\section{Results}

The groups of patients receiving each of the three oral rehydration solutions were easily comparable (Table 2), but the mean dehydration percentage was greater in the standard $\mathrm{ORS}_{60}$ group than in the other two groups. This difference was reflected in the amounts of fluid that the patients actually received in the first six hours (Table 3). The amounts of each ORS given within the first six hours corresponded closely to the original plan of $2 \times 2 / 3 \times$ acute weight loss- that is, the treatment could be carried out as planned in all the patients. A nasogastric tube was commonly used: 12 children in the ORS $60^{-}-\mathrm{Gly}_{110}$ group, 11 in the $\mathrm{ORS}_{60}-\mathrm{Gly}_{60}$, and 13 in the ORS $_{60}$ group were given at least part of the required amount through a nasogastric tube.

The children who received the standard $\mathrm{ORS}_{60}$ responded to treatment as expected on the basis of our previous experience. They showed good weight gain in the first 12 hours (Table 3), and the total duration of watery diarrhoea remained short (Table 4). Reintroduction of feedings was generally successful, the initial weight gain was maintained, and total time in hospital remained short (Tables 3 and 4). Two patients received supportive intravenous fluids, started on the second day of admission for continuous diarrhoea.

In contrast to the standard $\mathrm{ORS}_{60}$ group, the group receiving $\mathrm{ORS}_{60}$-Gly ${ }_{110}$ showed a poor weight gain in the first 12 hours (Table 3 ). The volume of stools was also somewhat (but not significantly) larger than in the $\mathrm{ORS}_{60}$ group (Table 3), as was the duration of watery diarrhoea (Table 4). Moreover, 


\section{Vesikari and Isolauri}

Table 2 Characteristics of patients on admission. All values (except rotavirus) are mean (SD)

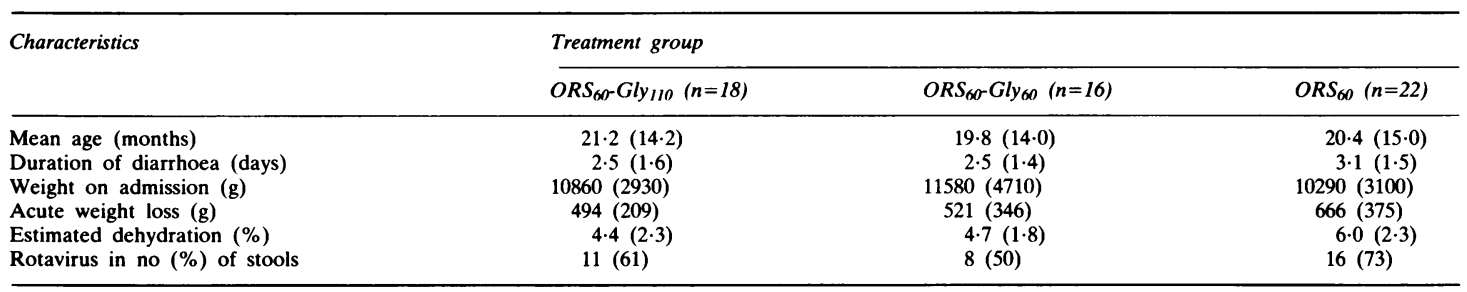

For estimated dehydration for $\mathrm{ORS}_{60}-\mathrm{Gly}_{110} v \mathrm{ORS}_{60}, \mathrm{p}<0 \cdot 05$ (Student's $t$ test). All other differences are not significant.

Table 3 Intake and output of fluids and sodium (values are mean (SD))

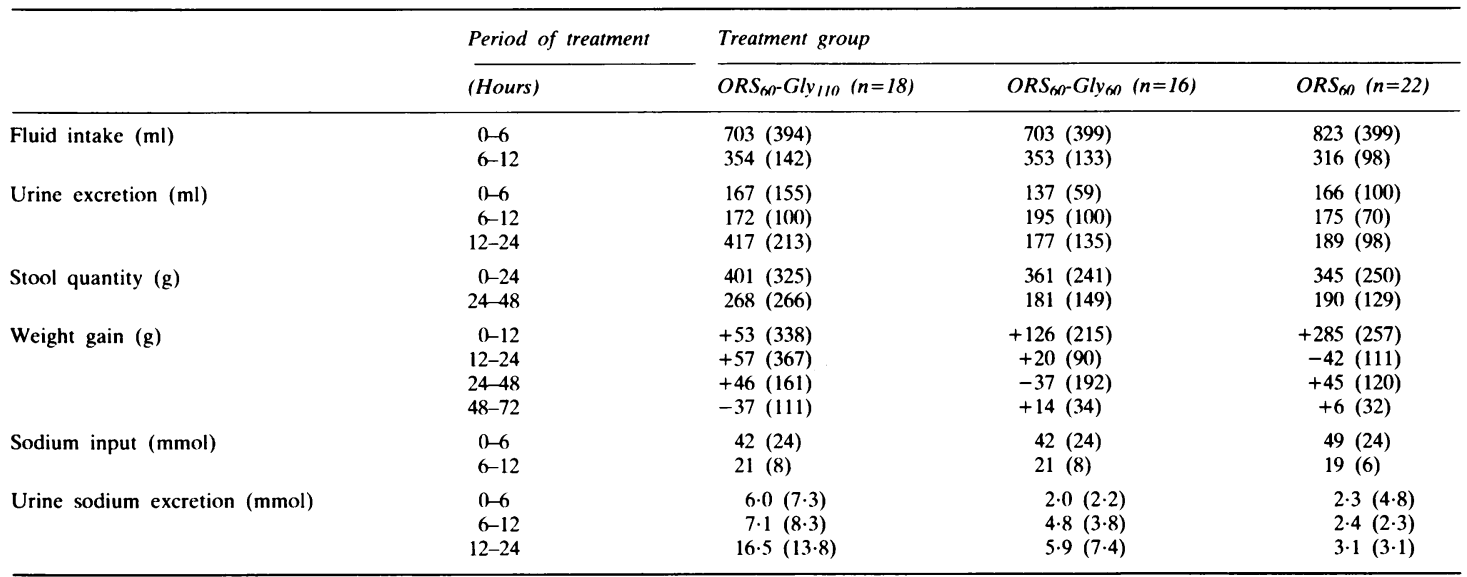

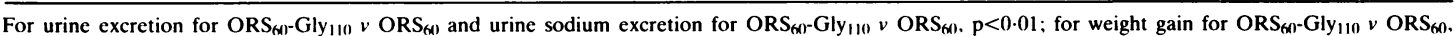
$\mathrm{p}<0.05$ (Student's $t$ test). All other differences are not significant.

Table 4 Clinical outcome of patients receiving oral rehydration

\begin{tabular}{|c|c|c|c|}
\hline & \multicolumn{3}{|c|}{ Treatment group } \\
\hline & $\begin{array}{l}O R S_{60-} G l y_{110} \\
(n=18)\end{array}$ & $\begin{array}{l}O_{(n=16)} \\
\left(n=G y_{60}\right.\end{array}$ & $\begin{array}{l}O R S_{60} \\
(n=22)\end{array}$ \\
\hline $\begin{array}{l}\text { Mean duration of } \\
\text { diarrhoea (hours) }\end{array}$ & $29(25)$ & $30(25)$ & $22(13)$ \\
\hline $\begin{array}{l}\text { Mean duration of } \\
\text { hospital stay (days) }\end{array}$ & $3 \cdot 3(1 \cdot 2)$ & $2.9(1.4)$ & $2 \cdot 7(1 \cdot 0)$ \\
\hline $\begin{array}{l}\text { Mean weight gain } \\
\text { by discharge }(g)\end{array}$ & +114 (187) & $148(215)$ & $314(315)$ \\
\hline
\end{tabular}

For mean weight gain by discharge ORS $_{60}-\mathrm{Gly}_{110} v \mathrm{ORS}_{60}, \mathrm{p}<0.05$. All other differences are not significant.

there was a pronounced difference in urine excretion: the mean urine volume at 12 to 24 hours in the $\mathrm{ORS}_{60}-\mathrm{Gly}_{110}$ group was significantly larger than in the $\mathrm{ORS}_{60}$ group (Table 3). Because of the inadequate rehydration after the first six hours four of the 18 children in the $\mathrm{ORS}_{60}-\mathrm{Gly}_{110}$ group were placed on intravenous treatment at that point, and one more patient received supportive intravenous fluids for continuing diarrhoea.

Compared with the $\mathrm{ORS}_{60}-\mathrm{Gly}_{110}$ group the children receiving $\mathrm{ORS}_{60}-\mathrm{Gly}_{60}$ fared much better, and there was little difference between the $\mathrm{ORS}_{60}-\mathrm{Gly}_{60}$ and $\mathrm{ORS}_{60}$ groups in the outcome (Tables 3 and 4). The mean weight gain at 12 hours in the $\mathrm{ORS}_{60^{-}}$ Gly $_{60}$ group was less than in the $\mathrm{ORS}_{60}$ group, but this could partly be explained by the lower degree of initial dehydration and smaller volume of ORS given (Tables 2 and 3 ). The urine and stool volumes in the two groups were quite similar in the follow up period (Table 3). In one case of the 16 in the $\mathrm{ORS}_{60}-\mathrm{Gly}_{60}$ group rehydration after six hours was considered inadequate and one child was transferred to intravenous treatment; one more child received 'supportive' intravenous fluids at a later time.

Rehydration was also measured by packed cell volume, total plasma protein concentrations, and blood acid-base analysis during rehydration at six, 
12, and 24 hours after treatment (data not shown). As the initial dehydration was only mild to moderate it was not possible to detect appreciable differences in the rehydration rate between the groups using these indicators. The children receiving $\mathrm{ORS}_{60^{-}}$ Gly $_{110}$ tended to remain more acidotic at 12 and 24 hours of treatment than children in the other two groups, but the difference was not significant.

The calculated sodium input in the first six and 12 hours of treatment and the corresponding urinary excretions up to 24 hours are shown in Table 3 . The urinary sodium excretion in the $\mathrm{ORS}_{60}$-Gly ${ }_{110}$ group was higher than in the other two groups throughout that period. In the $\mathrm{ORS}_{60}$-Gly $_{60}$ group the mean sodium excretion was also slightly higher than in the $\mathrm{ORS}_{60}$ group. In the latter group urinary sodium excretion remained low up to 24 hours, indicating that most of the sodium input was used for replacing sodium deficit. The serum sodium concentrations remained unchanged in all three groups during rehydration (data not shown). There were no changes in serum potassium or chloride concentrations either.

The daily weight changes in all three groups are presented in Table 3, and the overall weight gain by the time of discharge in Table 4. In general, the initial weight gain after rehydration was maintained in all groups, and the differences between groups remained similar throughout the hospital stay.

\section{Discussion}

The present experience with glycine in an oral rehydration solution containing $60 \mathrm{mmol} / \mathrm{l}$ sodium was not very encouraging as glycine seemed to cause osmotic diarrhoea and diuresis, or both. Initially, our research was prompted by the findings of Patra et al, who showed that an ORS of the WHO formula supplemented with $111 \mathrm{mmol} / \mathrm{l}$ of glycine was more effective than ordinary ORS-WHO for treatment of acute diarrhoeal dehydration. ${ }^{2}{ }^{3}$ It is therefore necessary to search for explanations for the apparently different experience.

The sodium concentration in our solutions was intentionally kept at $60 \mathrm{mmol} / \mathrm{l}$ as we believe this should be sufficient for an 'all purpose' (outpatient and inpatient) oral rehydration solution in our conditions where most of the patients with acute diarrhoea are likely to be mildly to moderately dehydrated with normal serum sodium concentrations. ${ }^{8}$ Thus the glycine:sodium ratio in the first glycine supplemented solution, $\mathrm{ORS}_{60}-\mathrm{Gly}_{110}$, was not optimal as it is known that the molar ratio for best net absorption should be roughly $1: 1 .^{5}$ Excess glycine in the slightly hypertonic solution could conceivably cause osmotic penalty, resulting in increased stool volume, as was observed in the patient group receiving $\mathrm{ORS}_{60}-\mathrm{Gly}_{110}$. However, osmotic diarrhoea and somewhat larger stool volume in the first 48 hours does not seem to be a sufficient explanation for the poor weight gain in these children. The same children also had significantly greater urine volume between 12 and 24 hours, suggesting that most of the $\mathrm{ORS}_{60}$-Gly $_{110}$ solution was actually absorbed but part of the absorbed fluid was later excreted in urine. A probable mechanism might be excretion of excess glycine in the urine with resulting osmotic diuresis. Unfortunately, we did not measure urinary excretion of glycine directly. When in the second solution, $\mathrm{ORS}_{60}-\mathrm{Gly}_{60}$, the quantity of glycine was reduced (to a molar ratio 1:1 with sodium) no such increase in urine volume was seen despite the fact that the solution was apparently well absorbed.

Different aetiology of diarrhoea in our patients and those of Patra $\mathrm{et} \mathrm{al}^{3}$ could also be responsible for the different experience of the glycine supplemented ORS. Most of our patients had rotavirus diarrhoea, whereas the patients of Patra et al in India had predominantly secretory diarrhoea due to Vibrio cholerae or Escherichia coli. ${ }^{3}$ The absorption of glycine could differ in diarrhoeas of different pathogenetic mechanism. In toxigenic secretory diarrhoea the gut epithelium remains intact, and the absorption is effective throughout the length of the small intestine. In contrast, in rotavirus diarrhoea there is structural damage, particularly in the proximal small intestine, where glycine absorption is supposed to take place. Thus it is possible that glycine absorption is reduced in rotavirus but not in toxigenic diarrhoea, whereas glucose might be equally effective as a carrier for sodium coupled water absorption in both conditions. Furthermore, rotavirus infection might cause more metabolic stress than secretory diarrhoea due to $E$. coli, and utilisation of glycine in the body could then be less effective in rotavirus diarrhoea. Under such a catabolic effect excess glycine would be excreted.

Another methodological difference between the studies was that we gave only a precalculated amount of ORS for rapid rehydration to all the patients, whereas Patra $e t$ al continued to administer the solutions ad libitum over a long period, consistent with the long duration of toxigenic diarrhoea. ${ }^{3}$ With this method the children receiving glycine fortified ORS consumed less of the solution and had a shorter duration of diarrhoea.

In summary we have shown that glycine can replace some of the glucose in our 'established' oral rehydration solution containing sodium $60 \mathrm{mmol} / \mathrm{l}$ and glucose $144 \mathrm{mmol} / \mathrm{l}$, but the resulting solution with glycine $60 \mathrm{mmol} / \mathrm{l}$ and glucose $80 \mathrm{mmol} / \mathrm{l}$ has no 
advantage over a solution with glucose alone. Addition of more glycine is likely to result in osmotic diarrhoea or diuresis, or both. The water absorption properties of $\mathrm{ORS}_{60}$ could possibly be improved by a still smaller amount than $60 \mathrm{mmol} / \mathrm{l}$ of glycine or another amino acid or dipeptide. ${ }^{2}$ Considering the present experience it will be of great importance to test any such experimental solution in the actual patient population, which in our conditions means young children with rotavirus diarrhoea.

The dedicated work and attention of the nursing staff of ward numbers 1 and 4 of the Department of Paediatrics, Tampere University Central Hospital, was essential for the success of the present study.

\section{References}

1 World Health Organisation. A manual for the treatment of acute diarrhoea WHO/CDD/SER. Geneva: WHO, 1984.

2 Mahalanabis D, Patra FC. In search of a super oral rehydration solution: can optimum use of organic solute-mediated sodium absorption lead to the development of an absorption promoting drug. Journal of Diarrhoeal Diseases Research 1983;1:76-81.

${ }^{3}$ Patra FC, Mahalanabis D, Jalan KN, Sen A, Banerjee P. In search of a super solution: controlled trial of glycine-glucose oral rehydration solution in infantile diarrhoea. Acta Paediatr Scand 1984;73:18-21.

${ }^{4}$ Patra FC, Mahalanabis D, Jalan KN, Sen A, Banerjee P. Is oral rice electrolyte solution superior to glucose electrolyte solution in infantile diarrhoea. Arch Dis Child 1982;57:910-2.

5 Hellier MD, Thirumalai C, Holdsworth CD. The effect of amino acids and dipeptides on sodium water absorption in man. Gut 1973;14:41-5.

6 Nalin DR, Cash RA, Rahman M, Yunus MD. Effect of glycine and glucose on sodium and water absorption in patients with cholera. Gut 1970;11:768-72.

${ }^{7}$ Desjeux J-F, Tannenbaum C, Tai Y-H, Curran PF. Effects of sugars and amino acids on sodium movement across small intestine. Am J Dis Child 1977;131:331-40.

${ }^{8}$ Isolauri E. Evaluation of an oral rehydration solution with $\mathrm{Na}^{+}$ $60 \mathrm{mmol} / \mathrm{l}$ in infants hospitalized for acute diarrhoea or treated as outpatients. Acta Paediatr Scand 1985;74:643-9.

Correspondence to Dr T Vesikari, University of Tampere, Department of Clinical Sciences, Teiskontie 35, 33520 Tampere 52, Finland.

Received 10 January 1986 